\title{
Neutrophil recruitment and phagocytosis of boar spermatozoa after artificial insemination of sows, and the effects of inseminate volume, sperm dose and specific additives in the extender
}

\author{
A. Matthijs ${ }^{1}$, B. Engel ${ }^{2}$ and H. Woelders ${ }^{1 *}$ \\ ${ }^{1}$ Division of Animal Sciences, and ${ }^{2}$ Division of Infectious Diseases and Quality, Institute for Animal \\ Science and Health (ID-Lelystad), PO Box 65, 8200 AB Lelystad, The Netherlands
}

In this study the recruitment of leucocytes and phagocytosis of spermatozoa after artificial insemination of multiparous sows was investigated. In Expt 1, groups of sows received either no inseminate $(n=6)$ or inseminates with various concentrations of spermatozoa and seminal plasma or different inseminate volumes $(n=9$ per group). In Expt 2, groups of sows received inseminates containing no addition, caffeine $+\mathrm{CaCl}_{2}$, or excess EDTA $(n=6$ per group). Leucocytes and spermatozoa were counted in the collected backflow from the vulva, and in the PBS flushings of the genital tract of sows killed at $4 \mathrm{~h}$ after insemination. Tissue homogenates were checked for remaining spermatozoa. Leucocyte recruitment did not depend on the presence of seminal plasma or spermatozoa. In the control groups about $43 \%$ of the inseminated spermatozoa were found in the backflow and $5 \%$ in the genital tract. Many spermatozoa could be recognized inside polymorphonuclear leucocytes. With an inseminate volume of $20 \mathrm{ml}$ instead of $80 \mathrm{ml}$, fewer spermatozoa were found in the backflow and more (non-phagocytosed) spermatozoa were recovered in the uterus $(P \leqslant 0.05)$. With a sperm dose of $0.24 \times 10^{9}$ instead of $2.4 \times 10^{9}$, a higher percentage of the inseminated spermatozoa was recovered in the oviducts $(P \leqslant 0.05)$. The use of caffeine $+\mathrm{CaCl}_{2}$ resulted in lower recruitment of leucocytes $(P \leqslant 0.05)$ and a higher number of non-phagocytosed spermatozoa in the uterus $(P \leqslant 0.01)$ compared with controls. The numbers of spermatozoa in the oviducts were not different. Insemination with excess EDTA had no positive effects on the number of spermatozoa in the genital tract.

\section{Introduction}

The purpose of insemination is that an adequate population of spermatozoa can be established and maintained at the site of fertilization until ovulation has taken place. The sperm dose presently used in artificial insemination $(\mathrm{Al})$ in pigs is approximately $2.5-3.0 \times 10^{9}$ spermatozoa in $80-100 \mathrm{ml}$ extender. The pig Al industry is trying to achieve a reduction of the number of inseminated spermatozoa per dose. However, sufficient fertile spermatozoa need to be present in the oviducts at the time of ovulation. In pigs, the time of ovulation relative to the onset of oestrous behaviour cannot be predicted exactly and varies considerably among sows (Soede et al., 1995). Consequently, the viability of the sperm population at the site of fertilization may need to be retained for $>24 \mathrm{~h}$.

*Correspondence

Email: h.woelders@id.wag-ur.nl

A patent has been filed that covers the use of phosphodiesterase inhibitors to reduce phagocytosis of spermatozoa.
Establishment of a sperm population in the oviducts occurs rapidly after insemination, as spermatozoa are observed in the oviducts as early as 5-15 min after insemination (Burger, 1952; First et al., 1968; Baker and Degen, 1972). The sperm population in the oviducts is maintained and increased by ongoing migration from the uterine horns during the first $24 \mathrm{~h}$ after insemination (Rigby, 1966; Pursel et al., 1978). At the same time, the number of spermatozoa in the uterus decreases markedly, decreasing to a few per cent of the inseminated number of spermatozoa in a few hours (First et al., 1968; Pursel et al., 1978; Viring, 1980; Viring and Einarsson, 1981; Kamerman, 1994), and reaching 0.1\% at $24 \mathrm{~h}$ after insemination (First et al., 1968; Pursel et al., 1978).

During the first $2-4 \mathrm{~h}$ after insemination, a considerable amount of semen flows back through the cervix and vagina, and is then voided through the vulva (Viring and Einarsson, 1981; Kamerman, 1994; Steverink et al., 1998). Another cause of loss of spermatozoa is phagocytosis by polymorphonuclear leucocytes (PMNs). (Lovell and Getty, 1968; Pursel et al., 1978; Kamerman, 1994). The clearance of the uterus after insemination 
has been observed in other mammalian species too and is believed to be a normal physiological process, serving to prepare the uterus for the reception of the embryo or embryos.

Insemination triggers a massive influx of PMNs into the uterine lumen (Lovell and Getty, 1968; Pursel et al., 1978; Rozeboom et al., 1998, 1999). In oestrous sows large numbers of PMNs are located in cell layers underneath the epithelium (Engelhardt et al., 1997; Bischof et al., 1994). Several factors may contribute to the recruitment of PMNs in pigs. Rozeboom $(1998,1999)$ found that extender alone could elicit an early response, but spermatozoa triggered additional recruitment at $12 \mathrm{~h}$ after insemination. In contrast, Engelhardt et al. (1997) reported that seminal plasma, and not spermatozoa, triggered the influx of PMNs into the stroma and epithelium of the endometrium of sows.

Backflow of semen, as well as recruitment of PMNs and the ensuing phagocytosis of spermatozoa, may be influenced by the volume and sperm concentration of the inseminate. In the first part of this study, we investigated the effects of varying the inseminate volume, sperm dose, presence of seminal plasma on recruitment of PMNs, semen backflow and phagocytosis of spermatozoa in the first $4 \mathrm{~h}$ after insemination of multiparous sows.

In the second part of this study, the possibility of modulating phagocytosis of spermatozoa in sows by using specific additives to the inseminate was investigated. In earlier studies both caffeine $\left(+\mathrm{CaCl}_{2}\right)$ (Woelders and Matthijs, 2001) and EDTA (A. Matthijs and $\mathrm{H}$. Woelders, unpublished) were found to reduce phagocytosis of spermatozoa in vitro. Therefore, the second part of the present study investigates the effects of addition of caffeine $+\mathrm{CaCl}_{2}$ or excess EDTA $\left(25 \mathrm{~mol} \mathrm{I}^{-1}\right.$ ) to the inseminates of sows on the number of PMNs recruited during $4 \mathrm{~h}$ after insemination and on the number of spermatozoa present in the uterus and oviducts at $4 \mathrm{~h}$ after insemination.

\section{Materials and Methods}

\section{Animals}

Both series of experiments reported were approved by the 'Dier-Experiment-Commissie' (DEC) animal experiment committee, the official body, instituted according to Dutch law, to review all experiments involving animals.

For each replicate, eight multiparous Dutch Landrace $\times$ Yorkshire sows (parity ranging from 3 to 12 ) were purchased from a Dutch breeding farm. On the day of weaning (day 1 ), they were transported to the pig facility at the Institute for Animal Science and Health, where they were housed individually. On the morning of day 4 , the sows received an intramuscular injection of 750 iu hCG (AUV, Cuijk), with a $30 \mathrm{~min}$ interval between the consecutive sows, for synchronization of ovulation.

\section{Preparation of semen}

Two Yorkshire breeding boars of proven fertility, at the Al station in Bunnik, were used per series of experiments. Semen of one boar was used per replicate. The semen was collected using routine Al methods and the initial sperm concentration was determined turbidimetrically. The semen was diluted with an equal volume of Beltsville Thawing Solution (BTS; Johnson et al., 1988) and transported at $17^{\circ} \mathrm{C}$ to the Institute. Further handling was performed at $17^{\circ} \mathrm{C}$.

In Expt 1, the semen was further extended with BTS to $0.12 \times 10^{9} \mathrm{cells} \mathrm{ml}^{-1}$. The spermatozoa were stained by addition of $40 \mu \mathrm{mol} \mathrm{I^{-1 }}$ of the DNA-binding fluorescent dye Hoechst 33342 (Sigma, Brunswich chemie, Amsterdam). For preparation of sperm-free seminal plasma, $25 \mathrm{ml}$ of the semen preparation was centrifuged for $10 \mathrm{~min}$ at $1000 \mathrm{~g}$. The supernatant was centrifuged once more at $3000 \mathrm{~g}$. The semen and seminal plasma were stored overnight at $17^{\circ} \mathrm{C}$. The next day, using the semen, the seminal plasma, and BTS in appropriate amounts, the following inseminates were prepared: (1) $2.4 \times 10^{9}$ spermatozoa in $80 \mathrm{ml}$, (2) $2.4 \times 10^{9}$ spermatozoa in $20 \mathrm{ml}$, (3) $0.24 \times 10^{9}$ spermatozoa in $80 \mathrm{ml}$, (4) diluted seminal plasma in $80 \mathrm{ml}$ and (5) $80 \mathrm{ml}$ BTS. The exact volume of seminal plasma in inseminates (1)-(4) varied between replicates, depending on the sperm concentration in the ejaculate. Averaged over the replicates, the volume of seminal plasma was $2 \mathrm{ml}$ per $10^{9}$ spermatozoa. Per replicate, the inseminate with sperm-free seminal plasma in BTS contained exactly the same volume of seminal plasma as the inseminates with $2.4 \times 10^{9}$ spermatozoa. Small samples were taken from the prepared inseminates (1)-(3) for evaluation of sperm viability and sperm concentration. Then, all prepared inseminates were transferred into insemination flasks and transported in an insulated box to the pig facility.

In Expt 2, three aliquots of semen, each containing $2 \times 10^{9}$ spermatozoa were treated in parallel as follows. One aliquot was extended with BTS to a volume of 160 $\mathrm{ml}$; the second was extended with BTS to a volume of $80 \mathrm{ml}$; and the third was extended with modified BTS (BTS-EDTA) to a volume of $160 \mathrm{ml}$. The modified BTS contained $25 \mathrm{mmol}$ instead of $3.4 \mathrm{mmol} \mathrm{Na} \mathrm{Na}_{2}$ ETA $\mathrm{I}^{-1}$ and $20 \%$ lower concentrations of the other solutes. The osmolality and $\mathrm{pH}$ of BTS-EDTA was equal to that of normal BTS. All three preparations of semen were stained by addition of $10 \mu \mathrm{mol}$ Hoechst 33342 $\mathrm{I}^{-1}$, and stored overnight at $17^{\circ} \mathrm{C}$. The next day, small samples were taken for evaluation of sperm viability and sperm concentration. Then, the three semen preparations were each divided into equal volumes, which were transferred into insemination flasks. In addition, two insemination flasks were prepared containing $40 \mathrm{ml}$ 
2.3 mmol caffeine $\mathrm{I}^{-1}$ (Sigma) in a modified BTS, in which the $\mathrm{Na}_{2}$ EDTA was omitted and replaced by $6 \mathrm{mmol} \mathrm{CaCl} \mathrm{I}^{-1}$ (BTS-caffeine $+\mathrm{Ca}^{2+}$ ). All flasks were transported in an insulated box to the pig facility. Before the viability evaluations, the sample with the twofold higher semen concentration was mixed with an equal volume of BTS-caffeine $+\mathrm{Ca}^{2+}$.

\section{Semen assessment just before insemination}

The percentage of motile spermatozoa was estimated at $38^{\circ} \mathrm{C}$, using phase-contrast microscopy at $\times 100$ magnification. Acrosome morphology was assessed in wet mounts after fixation with glutaraldehyde (Fluka, Brunswich chemie, Amsterdam), using phase-contrast microscopy at $\times 400$ magnification. Per sample, 200 spermatozoa were classified as described by Pursel et al. (1972). The final sperm concentration per inseminate was determined using a haemocytometer.

\section{Insemination and slaughter}

In the early morning of day 5 , five or six sows that exhibited a clear standing heat reflex in the presence of the boar were assigned at random to the treatment groups. The sows were inseminated on the same morning, approximately $26-27 \mathrm{~h}$ after the injection of hCG.

In Expt 1, per replicate, five sows were inseminated at $1 \mathrm{~h}$ intervals with the inseminates (1), (2), (3), (4) or (5) described above. There were nine replicates. One boar was used in four replicates; another boar was used in five replicates. In six of the nine replicates, a sixth sow was included that was not inseminated ('treatment $0^{\prime}$ ). In two other replicates a sixth sow was included that was not inseminated, but the sow was housed for an additional 8 days before being investigated in the same way as the other sows.

In Expt 2, per replicate (three replicates), the six sows were inseminated at 35 min intervals using either (1) $1 \times 10^{9}$ spermatozoa in $80 \mathrm{ml}$ BTS (control group), (2) $1 \times 10^{9}$ spermatozoa in $40 \mathrm{ml}$ BTS followed immediately by $40 \mathrm{ml}$ of BTS-caffeine/Ca or (3) $1 \times 10^{9}$ spermatozoa in $80 \mathrm{ml}$ BTS-EDTA. Treatments $(1,2$ and 3 ) within replicates were applied successively according to the following cyclic design: $1-2-3-1-2-3 / 2-3-1-2-$ $3-1 / 3-1-2-3-1-2$. One boar was used in one replicate; another boar was used in two replicates.

Insemination was performed while applying back pressure, using a spiral tip catheter (Nifa Instruments, Leeuwarden) lubricated with a sterile bacteriostatic jelly (Johnson \& Johnson, Nifa instruments, Leeuwarden). During insemination, a colostomy bag (Combihesive, Convatec, Woerden) was held around the vulva to collect possible backflow of semen. After insemination, the colostomy bag was connected onto its collar, which was fixed around the vulva of the sow with tape and cyanoacrylate glue. Whenever needed, the colostomy bag was replaced. An aliquot from each colostomy bag was fixed with $0.5 \%(\mathrm{v} / \mathrm{v})$ glutaraldehyde (Fluka, Brunswich Chemie, Amsterdam) and stored at $4{ }^{\circ} \mathrm{C}$. The inseminated sows were killed consecutively at $4 \mathrm{~h}$ after insemination. The non-inseminated sow in Expt 1 was killed before the other sows. The sows were killed by intravenous injection of $10 \mathrm{ml}$ of T61 (200 mg embutramide, $50 \mathrm{mg}$ mebezonium iodide and $5 \mathrm{mg}$ tetracain hydrochloride $\mathrm{ml}^{-1}$; AUV, Cuijk) and then were exsanguinated from the neck artery. After the abdomen was opened, clamps were placed to separate the different parts of the genital tract. The clamps on the distal ends of the oviducts were placed approximately $5 \mathrm{~mm}$ from the beginning of the uterine horn, such that the oviduct was clearly separated from the tip of the uterine horn, to prevent contamination of the oviducts with spermatozoa from the tip of the horn. The genital tract, with the exception of the vulva, was removed as quickly as possible and transported on ice to the laboratory.

\section{Flushing and sampling of the genital tract}

PBS was kept on ice. Oviducts, right uterine horn, left uterine horn plus corpus, cervix, and vagina were separated. Vagina and cervix were cut longitudinally, and the inside was 'massaged' in $100 \mathrm{ml} \mathrm{PBS}$. This was repeated with a new volume of PBS. The right uterine horn, and the left uterine horn plus corpus uteri were each filled with $35 \mathrm{ml}$ of PBS, which was forced in and out of the length of the horns several times by using the force of gravity. This was repeated twice with fresh PBS. The oviducts were flushed by placing $10 \mathrm{ml}$ of PBS in the infundibulum, which was forced through the ampulla and isthmus. This was repeated twice. For each part of the genital tract, the volumes of PBS collected were pooled, and an aliquot was fixed with $0.5 \%$ glutaraldehyde and stored at $4{ }^{\circ} \mathrm{C}$. The parts of the genital tract were weighed (left and right oviducts were taken together) and then ground in a mince-meat mill. A subsample of the homogenate was diluted with an equal volume of PBS and then homogenized in a Sorvall mixer (Meyvis \& Co., Bergen op Zoom) for 5 min at maximum speed, and stored at $-20^{\circ} \mathrm{C}$. The first results showed that there were few spermatozoa in the homogenates of vagina, cervix and uterus. Because of the relatively small contribution of cervix and vagina, these parts were not homogenized in the later replicates. In the oviducts, however, the majority of the spermatozoa (approximately two-thirds) was recovered in the homogenates. As the oviducts did not contain appreciable numbers of PMNs (see also Rodriguez-Martinez et al., 1990), in Expt 2 oviducts were directly homogenized without being flushed, and all spermatozoa were counted in the homogenates.

\section{Microscopic evaluation of the samples}

Flushings and semen backflow. The number of PMNs, and the total number of spermatozoa (free spermatozoa + 
spermatozoa inside PMNs) were determined by counting cells in Kova haemocytometer slides (Instruchemie BV, Hilversum), using phase-contrast microscopy at $x$ 200 magnification. In most cases, at least 100 cells per sample were counted. In samples with extremely low numbers of cells, at least 25 cells were counted. Neutrophils could be distinguished from other leucocytes by phase-contrast microscopy without differential staining. This was validated by comparison to May-Grünwald or Giemsa-stained smears. Comparisons based on evaluation of 400 leucocytes with each method differed less than $2 \%$. When combined phase-contrast and fluorescence microscopy were used, the percentage of phagocytosed spermatozoa was determined in wet mounts at $\times 400$ magnification. The phagocytosed fluorescent sperm nuclei could be distinguished clearly inside the PMNs. In almost all cases, 200 spermatozoa per sample were evaluated to determine whether they were inside or outside the PMNs. In a few samples that had extremely low numbers of spermatozoa (from vagina and cervix) a minimum of 40 spermatozoa were evaluated.

Tissue homogenates. Samples were counted in a Bürker Türk haemocytometer, using combined phasecontrast and fluorescence microscopy at $\times 400$ magnification. The number of spermatozoa was determined within four $0.9 \mu \mathrm{l}$ grids. By focusing at different levels in the haemocytometer, the brightly fluorescent sperm heads or nuclei could be clearly distinguished in the milieu. In some of the oviduct homogenates, 12 haemocytometer grids were evaluated instead of four grids, because the number of spermatozoa was very low.

\section{Statistical analysis}

The results from one animal inseminated with BTScaffeine $+\mathrm{Ca}^{2+}$, were not included in the data set because after slaughter the uterus of this animal displayed clear symptoms of endometritis.

Count data were analysed as overdispersed Poisson data. Main effects for treatments and batches were introduced on the logarithmic scale, that is the effects on the original scale are multiplicative. Counts $y$ were obtained from the actual counts by multiplication by a factor $L$. $L$ is based on the dilution factor, starting volume and counted volume. The variance was assumed to be a multiple $(L+C)$ of the mean. Parameter $c$ accounts for variation in Poisson means between individuals, and was estimated from Pearson's chi-square statistic, in combination with maximum quasi-likelihood estimation similar to Engel and Te Brake (1993). Overdispersion was introduced by statistical weights, $w=1 /(L+C)$. For collection of backflow, where counts were summed over several bags, $w$ was taken as the harmonic mean of $w$ of the separate bags. For the number of recovered spermatozoa, $y$, expressed as a fraction $y / A$ of the inseminated number of spermatozoa, $A$, the
Table 1. Motility and acrosome intactness of boar spermatozoa in the inseminates just before insemination

\begin{tabular}{|c|c|c|}
\hline Inseminate & $\begin{array}{c}\text { Motile } \\
\text { spermatozoa } \\
(\%)\end{array}$ & $\begin{array}{l}\text { Spermatozoa with } \\
\text { normal apical ridge } \\
(\%)\end{array}$ \\
\hline \multicolumn{3}{|l|}{ Expt $1(n=9)$} \\
\hline Control $^{\mathrm{a}}$ & $70 \pm 2$ & $78.1 \pm 1.5$ \\
\hline Smaller volume ${ }^{b}$ & $73 \pm 1$ & $77.8 \pm 1.7$ \\
\hline Fewer spermatozoac & $32 \pm 5^{*}$ & $76.0 \pm 1.8$ \\
\hline \multicolumn{3}{|l|}{ Expt $2(n=3)$} \\
\hline Control $^{\mathrm{d}}$ & $74 \pm 3$ & $74.3 \pm 2.6$ \\
\hline BTS-caffeine $+\mathrm{Ca}^{2+\mathrm{e}}$ & $75 \pm 1$ & $75.6 \pm 0.9$ \\
\hline BTS-EDTA ${ }^{f}$ & $67 \pm 8$ & $78.7 \pm 0.7$ \\
\hline
\end{tabular}

Values are mean $\pm \mathrm{SE}$.

a $2.4 \times 10^{9}$ spermatozoa in $80 \mathrm{ml}$ Beltsville Thawing Solution (BTS).

b $2.4 \times 10^{9}$ spermatozoa in $20 \mathrm{ml}$ BTS.

${ }^{\mathrm{c}} 0.24 \times 10^{9}$ spermatozoa in $80 \mathrm{ml}$ BTS

$\mathrm{d}_{1} \times 10^{9}$ spermatozoa in $80 \mathrm{ml}$ BTS.

$\mathrm{e} 1 \times 10^{9}$ spermatozoa in $40 \mathrm{ml}$ BTS $+40 \mathrm{ml} \mathrm{BTS}$ with caffeine and $\mathrm{CaCl}_{2}$.

${ }^{\mathrm{f}} 1 \times 10^{9}$ spermatozoa in $80 \mathrm{ml}$ BTS with sevenfold more EDTA.

$* P<0.05$ compared with control and smaller volume groups of Expt 1.

main effects were introduced on the probit scale, to account for the fact that the data are fractions. Inverses of estimated variances were introduced as statistical weights. These variances were approximated by firstorder Taylor expansion. They were evaluated from results from separate analyses of recovered and inseminated amounts $y$ and $A$ in combination with a pooled estimate for the correlation between $y$ and $A$. When $y$ is a total over several parts of the genital tract, pooled correlations between counts for the different parts were used too. For the fractions of phagocytosed cells and for the fractions of non-phagocytosed cells relative to the amount of inseminated semen an analogous approach was used.

Approximate $F$ tests were based on the quasilikelihood ratio test (McCullagh, 1983). All calculations were performed with the statistical package Genstat 5 (1993).

\section{Results}

\section{Stage of oestrus}

Corpora rubra were present on the ovaries of 12 of the 51 (Expt 1) and of six of the 18 (Expt 2) inseminated sows, indicating that these animals had ovulated or were in the process of ovulation at the time of slaughter, that is $4 \mathrm{~h}$ after insemination. Ovaries of the other sows showed numerous pre-ovulatory follicles.

\section{Inseminate sperm viability}

There was no apparent difference in the average sperm motility or acrosome intactness among the boars used. Semen quality of the inseminates just before use was good (Table 1), except for the motility in Expt 1, treatment 
Table 2. Number of polymorphonuclear leucocytes $\left(\times 10^{9}\right)$ in parts of the genital tract of sows at $4 \mathrm{~h}$ after insemination, and in the backflow collected during $4 \mathrm{~h}$ after insemination (Expt 1)

\begin{tabular}{lcccrr}
\hline Treatment & Uterus & Cervix + vagina & Total tract & Backflow & Total \\
\hline Luteal phase $^{\mathrm{a}}$ & $<0.000001(2)$ & $<0.02(2)$ & $<0.02(2)$ & $0(2)$ & $<0.02(2)$ \\
Not inseminated $^{\mathrm{b}}$ & $0.23 \pm 0.18(6)^{*}$ & $0.05 \pm 0.03(6)^{\dagger}$ & $0.27 \pm 0.20(6)^{*}$ & $0(6)^{*}$ & $0.27 \pm 0.20(6)^{*}$ \\
Control $^{\mathrm{c}}$ & $1.44 \pm 0.38(9)$ & $0.22 \pm 0.05(9)$ & $1.66 \pm 0.42(9)$ & $1.43 \pm 0.55(8)$ & $3.18 \pm 0.93(8)$ \\
Smaller volume $^{\mathrm{d}}$ & $1.66 \pm 0.42(9)$ & $0.16 \pm 0.04(9)$ & $1.82 \pm 0.44(9)$ & $0.71 \pm 0.42(7)$ & $2.63 \pm 0.90(7)$ \\
Fewer spermatozoa $^{\mathrm{e}}$ & $2.58 \pm 0.53(9)$ & $0.22 \pm 0.05(9)$ & $2.80 \pm 0.56(9)$ & $1.87 \pm 0.63(8)$ & $4.98 \pm 1.17(8)$ \\
Seminal plasma $^{f}$ & $1.50 \pm 0.38(9)$ & $0.18 \pm 0.05(9)$ & $1.69 \pm 0.41(9)$ & $1.32 \pm 0.76(4)$ & $2.76 \pm 1.25(4)$ \\
Extender $^{\mathrm{g}}$ & $1.78 \pm 0.43(8)$ & $0.32 \pm 0.06(8)$ & $2.12 \pm 0.48(8)$ & $2.13 \pm 1.06(3)$ & $4.19 \pm 1.72(3)$ \\
\hline
\end{tabular}

Values are mean $\pm \mathrm{SE}(n)$.

a Non-inseminated sows in luteal phase.

${ }^{b}$ Non-inseminated oestrous sows.

${ }^{\mathrm{c}} 2.4 \times 10^{9}$ spermatozoa in $80 \mathrm{ml}$.

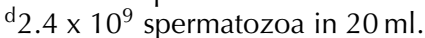

e $0.24 \times 10^{9}$ spermatozoa in $80 \mathrm{ml}$.

${ }^{\mathrm{f}}$ Amount of seminal plasma equivalent to that of control and smaller volume groups in $80 \mathrm{ml}$.

g $80 \mathrm{ml}$ Beltsville Thawing Solution (BTS) extender.

${ }^{*} P<0.05$ compared with all groups of inseminated sows.

${ }^{\dagger} P<0.05$ compared with controls, fewer spermatozoa, seminal plasma and extender groups.

with fewer spermatozoa $(P<0.05)$. In earlier work it was found that at high dilution of boar semen in BTS the expression of motility is suppressed, but can be restored by addition of seminal plasma or medium for in vitro fertilization (A. Matthijs and $\mathrm{H}$. Woelders, unpublished).

\section{Semen backflow}

Most of the backflow $(70-80 \%$ of the collected volume) was collected within the first hour after insemination. In Expt 1, many animals had urinated at some stage during collection, so a correct estimate of the volume of the vaginal discharge could not be obtained for all animals. In the 18 animals that had not urinated, the volume of the backflow collected in $4 \mathrm{~h}$ was $103 \pm$ $20 \%$ (mean $\pm \mathrm{SD}$ ) of the inseminate volume. In Expt 2, 11 of the 18 animals had urinated at some stage during collection, but the colostomy bags were changed frequently, and the bags contaminated with urine were discarded for the calculation of total volume of backflow. The volume of the backflow collected in $4 \mathrm{~h}$, expressed as a percentage of the inseminated volume, was $96 \pm$ $19.3 \%$ (mean $\pm \mathrm{SD}$ ) in the control group, $72 \pm 12.7 \%$ in the BTS-caffeine $+\mathrm{Ca}^{2+}$ group and $79 \pm 55.6 \%$ in the BTS-EDTA group. In the BTS-EDTA group, both the volume of backflow and the number of recovered spermatozoa in the backflow appeared to vary more than in the other two groups. In the BTS-EDTA group, the backflow of two animals contained $87 \%$ and $75 \%$ of the inseminated spermatozoa, respectively, whereas the backflow of two other animals contained only $4 \%$ and $3 \%$, respectively.

\section{PMNs}

The total number of PMNs found per sow varied markedly between the individual animals, but did not correlate with age or parity of the sow. The backflow of the inseminated sows contained large numbers of PMNs (Table 2, Fig. 1). The fractions collected in the first hour after insemination contained considerable numbers of PMNs, but in general most PMNs were found in the later fractions of backflow. More than $95 \%$ of the leucocytes in the backflow and in the uterine flushings were PMNs. In the cervix and vagina the percentage of PMNs was somewhat lower, varying from 60 to $90 \%$. Many of the PMNs in uterus, cervix, vagina and backflow contained phagocytosed spermatozoa. In the oviducts, only very small numbers of leucocytes were observed $\left((0.2 \pm 0.06) \times 10^{6}\right.$ cells per two oviducts; mean $\pm \mathrm{SE}, n=27), 20 \%$ of which were PMNs. The leucocytes from the oviducts did not contain phagocytosed spermatozoa.

In the luteal phase sows (that is, 8 days after the onset of oestrus), negligible numbers of PMNs were recovered from the genital tract (Table 2). The genital tracts of oestrous, non-inseminated sows already contained considerable numbers of PMNs (Table 2). In the inseminated sows however, the total numbers of PMNs were at least $\times 9$ higher $(P<0.01)$ than in noninseminated animals (Table 2). The differences among the five insemination groups were not significant. However, the (total) number of PMNs tended to be higher when less or no seminal plasma was present in the inseminate, compared with the groups inseminated with the routine quantity of seminal plasma (Table 2).

The total number of PMNs in the BTS-caffeine $+\mathrm{Ca}^{2+}$ group was significantly lower $(P<0.05)$ (approximately threefold lower) than in the control group (Fig. 1). The lower number of PMNs in the BTS-caffeine $+\mathrm{Ca}^{2+}$ group was apparent in the backflow and in the genital tract, but the difference from the controls was significant only in the combined data, that is, in the total number of 


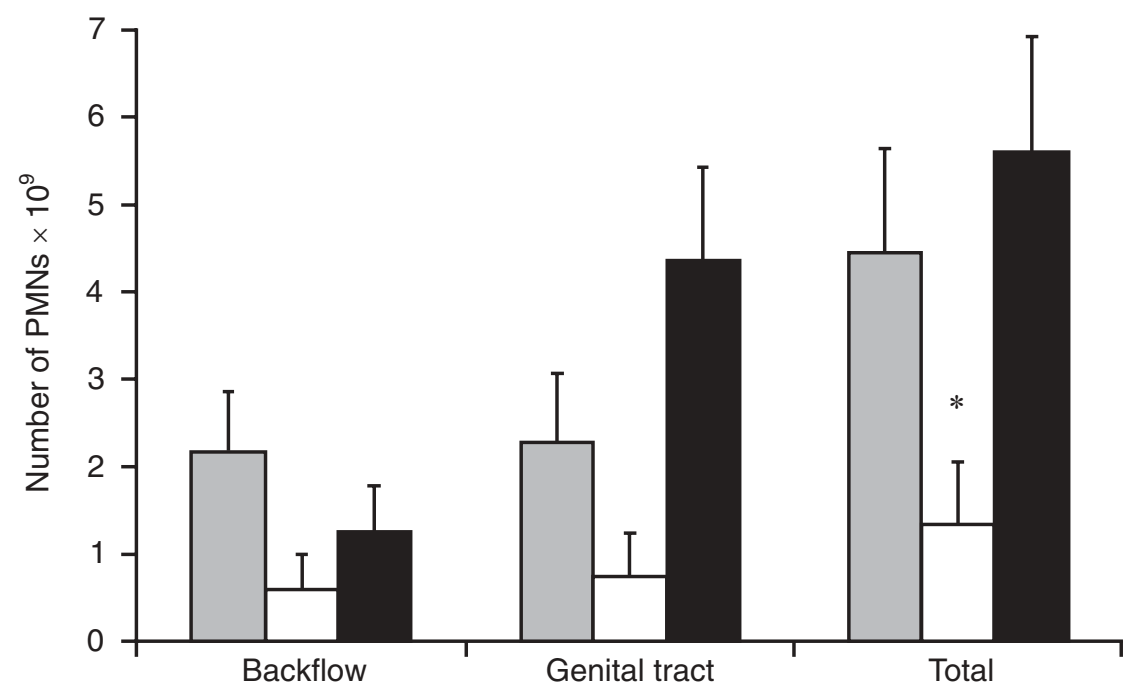

Fig. 1. Number of polymorphonuclear leucocytes (PMNs) in the backflow collected during $4 \mathrm{~h}$ after insemination, and in the genital tract of sows at $4 \mathrm{~h}$ after insemination (mean \pm SEM). Three groups of sows were inseminated with: $1 \times 10^{9}$ spermatozoa in $80 \mathrm{ml}$ Beltsville Thawing Solution (BTS) (controls, $\square, n=6$ ), or $1 \times 10^{9}$ spermatozoa in $40 \mathrm{ml}$ BTS followed by $40 \mathrm{ml}$ BTS-caffeine $+\mathrm{Ca}^{2+}(\square, n=5)$, or $1 \times 10^{9}$ spermatozoa in BTS-excess $\operatorname{EDTA}(\boldsymbol{\square}, n=6)$, respectively. ${ }^{*} P<0.05$ compared with the control and BTS-excess EDTA groups.

Table 3. Number of boar spermatozoa recovered in parts of the genital tract of sows at $4 \mathrm{~h}$ after insemination, and in the backflow collected during $4 \mathrm{~h}$ after insemination (Expt 1)

\begin{tabular}{|c|c|c|c|c|c|c|}
\hline & Oviducts $\left(\times 10^{-3}\right)$ & Uterus & Cervix + vagina & Total tract & Backflow & Total \\
\hline \multicolumn{7}{|c|}{ Spermatozoa outside PMNs } \\
\hline Control $^{\mathrm{a}}$ & $3.7 \pm 0.9(8)$ & $2.1 \pm 0.5(9)$ & $0.9 \pm 0.3(9)$ & $3.0 \pm 0.6(9)$ & $37.4 \pm 3.0(8)$ & $40.4 \pm 3.2(8)$ \\
\hline Smaller volume ${ }^{b}$ & $4.5 \pm 1.0(9)$ & $4.1 \pm 0.8(9)^{*}$ & $0.6 \pm 0.2(9)$ & $4.7 \pm 0.8(9)$ & $28.2 \pm 2.6(7)^{*}$ & $32.7 \pm 3.0(7)$ \\
\hline Fewer spermatozoa ${ }^{\mathrm{C}}$ & $10.0 \pm 4.4(9)^{*}$ & $2.6 \pm 1.2(9)$ & $1.2 \pm 0.7(9)$ & $4.0 \pm 1.6(9)$ & $31.0 \pm 6.4(8)$ & $36.1 \pm 7.1(8)$ \\
\hline \multicolumn{7}{|c|}{ Total detectable spermatozoa } \\
\hline Control & $3.7 \pm 0.9(8)$ & $2.8 \pm 0.6(9)$ & $1.7 \pm 0.4(9)$ & $4.5 \pm 0.8(9)$ & $42.5 \pm 2.8(8)$ & $47.1 \pm 2.7(8)$ \\
\hline Smaller & $4.5 \pm 1.0(9)$ & $5.8 \pm 0.9(9)^{* *}$ & $1.0 \pm 0.3(9)$ & $6.9 \pm 1.0(9)$ & $31.7 \pm 1.0(7)^{* *}$ & $38.7 \pm 2.5(7)^{*}$ \\
\hline Fewer spermatozoa & $10.0 \pm 4.4(9)^{*}$ & $8.2 \pm 3.1(9)^{*}$ & $3.3 \pm 1.5(9)$ & $11.5 \pm 3.9(9)^{*}$ & $47.5 \pm 8.7(8)$ & $59.2 \pm 9.1(8)$ \\
\hline
\end{tabular}

Values are mean $\pm \mathrm{SE}(n)$.

${ }^{a}$ Expressed as a percentage of the inseminate (inseminate contained $2.4 \times 10^{9}$ spermatozoa in $80 \mathrm{ml}$ ).

${ }^{b}$ Expressed as a percentage of the inseminate (inseminate contained $2.4 \times 10^{9}$ spermatozoa in $20 \mathrm{ml}$ ).

' Expressed as a percentage of the inseminate (inseminate contained $0.24 \times 10^{9}$ spermatozoa in $80 \mathrm{ml}$ ).

${ }^{*} P<0.05$ compared with the respective controls.

${ }^{* *} P<0.01$ compared with the respective controls.

PMNs: polymorphonuclear leucocytes.

PMNs. The total numbers of PMNs in the control and the BTS-EDTA groups were not significantly different.

\section{Spermatozoa}

The numbers of spermatozoa in the tissue homogenates of the uterus, cervix and vagina were relatively low: on average $5.0 \pm 2.5 \%$ of the recovered spermatozoa in Expt 1 and $7.3 \pm 3.5 \%$ in Expt 2. However, in the oviducts approximately two-thirds of the number of spermatozoa recovered were found in the tissue homogenates (Expt 1).
The factor 'Boar' had no significant influence on the number of spermatozoa recovered from the sows. In addition, there was no significant difference between sows that had or had not ovulated at the time of slaughter. As with the number of PMNs, the number of recovered spermatozoa varied considerably among sows. This variation was even more marked in the BTSEDTA group in Expt 2. The uterine lumen contained most $(70-85 \%)$ of the non-phagocytosed spermatozoa in the genital tract (Table 3). In all groups of sows inseminated with semen (except the BTS-caffeine $+\mathrm{Ca}^{2+}$ group of 


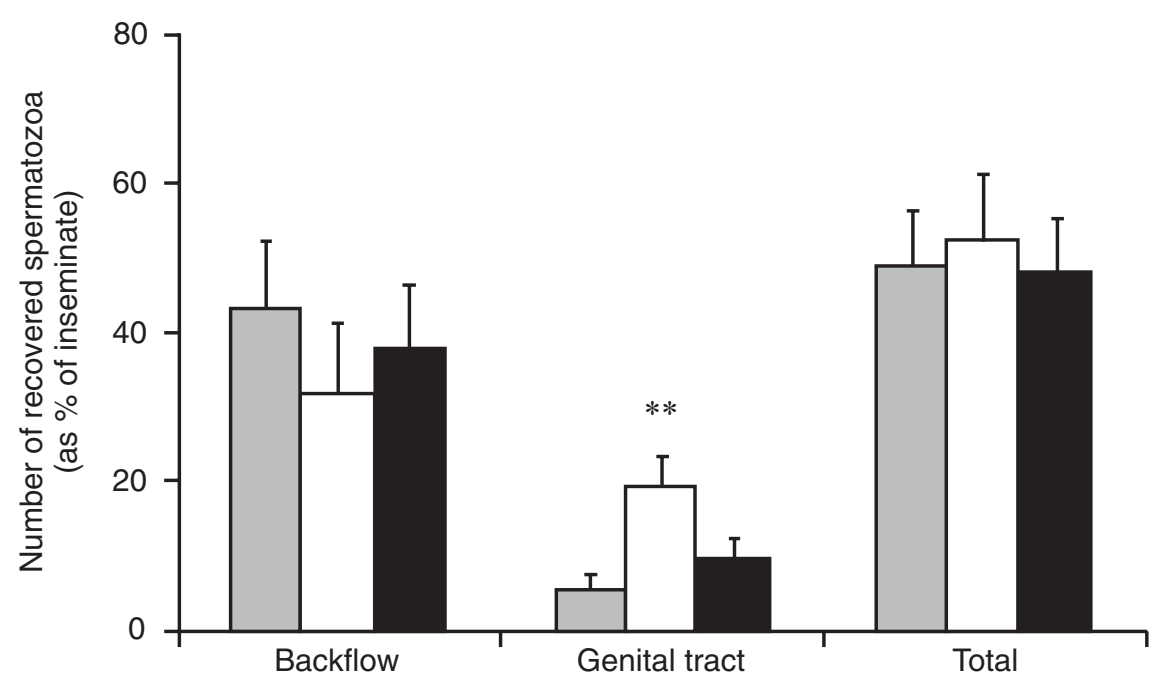

Fig. 2. Total recovered boar spermatozoa (inside + outside the leucocytes; expressed as percentage of inseminate) in the backflow collected during $4 \mathrm{~h}$ after insemination, and in the genital tract of sows at $4 \mathrm{~h}$ after insemination (mean \pm SEM, data are from the same animals (Fig. 1)). Three groups of sows had been inseminated with: $1 \times 10^{9}$ spermatozoa in $80 \mathrm{ml}$ Beltsville Thawing Solution (BTS) (reference group, $\square, n=6$ ), or $1 \times 10^{9}$ spermatozoa in $40 \mathrm{ml} \mathrm{BTS}$ followed by $40 \mathrm{ml} \mathrm{BTS}$-caffeine $+\mathrm{Ca}^{2+}(\square, n=5)$, or $1 \times 10^{9}$ spermatozoa in $\operatorname{BTS}$-excess $\operatorname{EDTA}(\boldsymbol{\square}, n=6)$, respectively. ${ }^{* *} P<0.01$ compared with the control group and $P=0.05$ compared with the BTS-excess EDTA group.

Expt 2), the number of non-phagocytosed spermatozoa in the uterus (or even in the entire genital tract) was only a few $(1-4 \%)$ of the inseminated number of spermatozoa (Table 3). Another few per cent of spermatozoa could be recognized in the genital tract inside PMN. The majority of the spermatozoa, about $40 \%$ of the inseminated number of spermatozoa, was found in the backflow (Table 3, Fig. 2). Most spermatozoa in the backflow were found in the first fractions (data not shown). About $50 \%$ of the inseminated spermatozoa could not be recovered (Table 3, Fig. 2), which we attribute to digestion of phagocytosed spermatozoa. The proportion of spermatozoa found inside PMNs was higher in the cervix and vagina than in the uterus (Tables 3 and 4). In the backflow, the percentage of spermatozoa inside PMNs was relatively modest.

Spermatozoa were present in the oviducts of all sows that received an inseminate containing spermatozoa. In Expt 1, in which the inseminate volume and sperm dose were varied, the restvariance (that is, after correcting for main effects), a weak but significant correlation was found between the number of spermatozoa found in the oviducts and the number of non-phagocytosed spermatozoa in the uterus $(r=0.46$, $P<0.05)$.

In the group of sows inseminated with an inseminate of $20 \mathrm{ml}$ rather than of $80 \mathrm{ml}$, the number of spermatozoa found in the backflow was significantly lower $(P<0.01)$ than in the controls (Table 3). The number of spermatozoa recovered from the genital tract tended to be higher (but
Table 4. Percentage of boar spermatozoa in polymorphonuclear leucocytes in parts of the genital tract at $4 \mathrm{~h}$ after insemination and in the backflow during $4 \mathrm{~h}$ after insemination (Expt 2)

\begin{tabular}{|c|c|c|c|c|}
\hline Inseminate & $n$ & Backflow & Vagina-cervix & Uterus \\
\hline $\mathrm{N}$ & 6 & & 71. & 66.5 \\
\hline BTS-caffeine $+\mathrm{Ca}^{2+b}$ & 5 & 15.1 & $46.9 \pm 8.6^{*}$ & $28.6 \pm 10.5^{*}$ \\
\hline BTS-EDTA ${ }^{\mathrm{c}}$ & 6 & $32.1 \pm 6.8$ & $79.9 \pm 6.3$ & $84.8 \pm 7.5$ \\
\hline
\end{tabular}

Values are mean \pm SE.

a $1 \times 10^{9}$ spermatozoa in $80 \mathrm{ml}$ normal Beltsville Thawing Solution (BTS).

b $1 \times 10^{9}$ spermatozoa in $40 \mathrm{ml} \mathrm{BTS}+40 \mathrm{ml}$ BTS with caffeine and $\mathrm{CaCl}_{2}$.

${ }^{\mathrm{c}} 1 \times 10^{9}$ spermatozoa in $80 \mathrm{ml}$ BTS with sevenfold more EDTA.

${ }^{*} P<0.05$ compared with normal BTS.

the difference was not significant; $P<0.06$ ) and the number of non-phagocytosed spermatozoa in the uterus was significantly higher in the smaller volume group than in the controls $(P<0.01)$, but the number of spermatozoa in the oviducts was not significantly different (Table 3).

In the group of sows inseminated with the tenfold lower sperm dosage $\left(0.24 \times 10^{9}\right.$ spermatozoa), the relative number of non-phagocytosed spermatozoa (that is, expressed as a percentage of the inseminated number of spermatozoa) in the oviducts was significantly higher $(P<0.05)$ than in the controls (Table 3$)$. For uterus and total tract the relative number of spermatozoa recovered (inside + outside PMNs) was also higher $(P<0.05)$ in the group with fewer spermatozoa than in the controls, but 


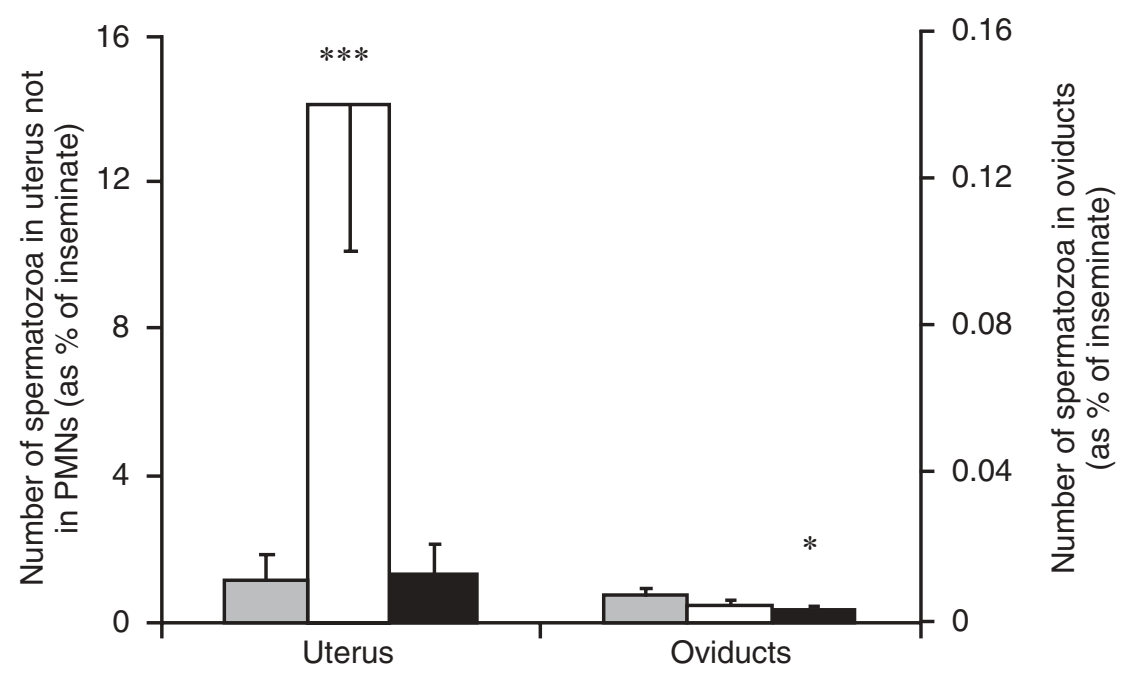

Fig. 3. Number of non-phagocytosed boar spermatozoa (expressed as a percentage of the inseminate) in uterus and oviducts, respectively, at $4 \mathrm{~h}$ after insemination of sows (mean \pm SEM, data are from the same animals (Fig. 1)). Three groups of sows had been inseminated with: $1 \times 10^{9}$ spermatozoa in $80 \mathrm{ml}$ Beltsville Thawing Solution (BTS) (control group, $\square, n=6$ ), or $1 \times 10^{9}$ spermatozoa in $40 \mathrm{ml}$ BTS followed by $40 \mathrm{ml}$ BTS-caffeine $+\mathrm{Ca}^{2+}(\square, n=5)$, or $1 \times 10^{9}$ spermatozoa in BTS-excess EDTA $(\boldsymbol{\square}, n=6)$, respectively. ${ }^{*} P<0.05$ compared with the control group. ${ }^{* * *} P<0.001$ compared with the control and BTS-excess groups. PMNs: polymorphonuclear leucocytes.

the relative number of non-phagocytosed spermatozoa was not significantly different.

In the BTS-caffeine $+\mathrm{Ca}^{2+}$ group, the number of spermatozoa recovered in the genital tract (inside + outside PMNs) was significantly $(P<0.01)$ higher than that in the controls (Fig. 2). In addition, a significantly greater $(P \leqslant 0.05)$ fraction of the recovered spermatozoa was seen outside PMNs (Table 4). The number of nonphagocytosed spermatozoa in the uterus was very much higher $(P<0.001)$ in the BTS-caffeine $+\mathrm{Ca}^{2+}$ group than in the controls (Fig. 3). However, the number of non-phagocytosed spermatozoa in the oviducts was not significantly different from that in the controls (Fig. 3).

In the BTS-EDTA group, the numbers of total recovered spermatozoa in the genital tract (Fig. 2) and of non-phagocytosed spermatozoa in the uterus (Fig. 3) were not significantly different from those in the controls. The number of spermatozoa in the oviducts was significantly lower $(P<0.05)$ than in the controls (Fig. 3).

\section{Discussion}

In the present study, the number of available spermatozoa in the genital tract was rapidly reduced after insemination to a few per cent of the inseminated number of spermatozoa within only $4 \mathrm{~h}$ after insemination. A considerable loss of spermatozoa was due to backflow of semen. The volume of collected backflow was on average the same as the volume of the inseminate. This finding shows that none or very little of the inseminated liquid was resorbed by the uterus. This was not attributable to the composition of the extender, as similar results were obtained when sows were inseminated with human infant oral rehydration solution, PBS or Tyrode's IVF medium (the present study, not shown).

Another important cause for the loss of spermatozoa is their phagocytosis by PMNs. Insemination resulted in a rapid recruitment of PMNs. The number of recovered PMNs exceeded the number of inseminated spermatozoa (cf. Pursel et al., 1978). Many PMNs could be seen to have phagocytosed spermatozoa. In the present study, it was clear that the recruitment of PMNs was triggered by the intromission of liquid into the uterus, rather than by the presence of spermatozoa or seminal plasma. The recruited number of PMNs in sows inseminated with only semen extender was not significantly different from that in sows inseminated with extended boar semen or seminal plasma in BTS. The recruitment did not seem to be triggered by a specific compound of BTS, as sows inseminated with Tyrode's medium, PBS or human infant oral rehydration solution had similar numbers of PMNs compared with sows inseminated with BTS (the present study, not shown). In addition, Rozeboom et al. (1998, 1999) found no difference in the number of PMNs in uterine lavages collected $6 \mathrm{~h}$ after insemination of gilts with either extended semen, seminal plasma or extender alone.

The use of fluorescent techniques enabled the detection of spermatozoa that could be hidden in folds or invaginations of the epithelium. Indeed, by homogenizing the tissue, it was found that a large proportion of the 
spermatozoa in the oviducts had not been recovered by repeated flushing. The average number of spermatozoa (flushings + homogenate) that were found in the oviducts $\left(9 \times 10^{4}\right.$ spermatozoa in the controls inseminated with $2.4 \times 10^{9}$ spermatozoa) was high compared with the numbers reported in the other studies, which vary from thousands (Du Mesnil du Buisson and Dauzier, 1955; Pursel et al., 1978) to tens of thousands (Viring and Einarsson, 1981), although in another paper the last authors reported numbers as high as $7.3 \times 10^{5}$ (Viring and Einarsson, 1980).

As all backflow was carefully collected, and because of the use of fluorescent spermatozoa, and the thorough screening for spermatozoa that had not been flushed out, large numbers of spermatozoa were probably not overlooked. The use of fluorescently labelled spermatozoa also allowed the recognition and quantitation of the spermatozoa inside PMNs. However, it is important to note that the spermatozoa are rapidly digested after being phagocytosed. It was shown in an in vitro study that fluorescently labelled boar spermatozoa can be digested by PMN within $1 \mathrm{~h}$ after being phagocytosed (Matthijs et al., 2000). In the present study approximately 50\% of the inseminated spermatozoa were not recovered and are assumed to have been digested.

The present results indicate that the loss of spermatozoa in the backflow can be reduced, and the number of non-phagocytosed spermatozoa retained in the uterus can be improved by reduction of the inseminate volume. The sows in the group with the inseminate volume of $20 \mathrm{ml}$ had a significantly higher number of nonphagocytosed spermatozoa in the uterus. The number of spermatozoa in the oviducts was not significantly higher than in the controls at $4 \mathrm{~h}$ after insemination, but the significantly larger sperm population in the uterus could be important for maintaining an adequate sperm population in the oviduct for a longer period after insemination. These results differ from those presented by Baker et al. (1968), who reported reduced sperm transport to the oviducts with inseminate volumes of $20 \mathrm{ml}$, compared with $100 \mathrm{ml}$.

With the lower sperm dose of only $0.24 \times 10^{9}$ spermatozoa, a lower absolute number of spermatozoa was found in the genital tract. However, the low sperm dose seems to be compensated to some extent by a lower efficiency of phagocytosis. The relative number of non-phagocytosed spermatozoa (that is, expressed as a percentage of the inseminated number of spermatozoa) was larger than in the controls (significantly larger for the oviducts), in spite of the fact that there were very few spermatozoa compared with the number of PMNs. There were significant numbers of spermatozoa in the oviducts of all sows in this group (on average $2.4 \times 10^{4}$ spermatozoa).

An important finding in this study was that addition of caffeine $+\mathrm{CaCl}_{2}$ to the inseminate markedly reduced the recruitment of PMNs. PMNs in the uterine lumen are probably recruited from a large population of PMNs in the basal region of the uterine epithelium (Bischof et al., 1994; Engelhardt et al., 1997). As caffeine is a non-specific phosphodiesterase inhibitor, the reduction of recruitment of PMNs by caffeine $+\mathrm{Ca}^{2+}$ could result from increased concentrations of CAMP in the PMNs or in the endometrial stroma cells. High concentrations of CAMP are reported to inhibit motility and chemotaxis of PMNs (Hill et al., 1975; Rivkin et al., 1975; Friedman et al., 1987; Harvath et al., 1991; Carrasco et al., 1997; De la Fuente et al., 1997).

Another important finding of the present study was that in sows inseminated with semen with caffeine + $\mathrm{CaCl}_{2}$ the number of non-phagocytosed spermatozoa in the genital tract at $4 \mathrm{~h}$ after insemination was 12 fold higher than in the controls. Addition of caffeine $+\mathrm{CaCl}_{2}$ did not affect the contractility of the uterus, compared with a control inseminate (E. G. Bouwman, N. M. Soede and B. Kemp, personal communication). In the present study, caffeine $+\mathrm{CaCl}_{2}$ had no significant effect on loss of spermatozoa by backflow. Thus, the results in the present study indicate that phagocytosis of spermatozoa was reduced by caffeine $+\mathrm{CaCl}_{2}$. The reduced number of $\mathrm{PMNs}$ present in the uterus may have contributed to reduced phagocytosis of spermatozoa. However, the number of PMNs was still many times greater than the number of spermatozoa at $4 \mathrm{~h}$ after insemination. There is no indication whether caffeine + $\mathrm{CaCl}_{2}$ affects the phagocytic activity of PMNs per se. Much of the reduction of phagocytosis of spermatozoa may be attributable to a reduction of the susceptibility of spermatozoa to phagocytosis by caffeine $+\mathrm{CaCl}_{2}$. It has been shown that incubation of boar spermatozoa with caffeine (especially in combination with $\mathrm{CaCl}_{2}$ ) at body temperature markedly reduced the phagocytosis of spermatozoa in vitro, which was mediated by an increase of the intracellular concentration of cAMP (Woelders and Matthijs, 2001). Treatment of the semen to induce capacitation in vitro is also reported to result in a strong reduction of phagocytosis in vitro (Matthijs et al., 2000). Caffeine accelerates some of the changes related to capacitation by affecting the intracellular content of cAMP in the spermatozoa (Fraser, 1995; Harrison et al., 1993, 1996). However, for reasons explained earlier (Woelders and Matthijs, 2001), capacitation is not a necessary precondition for the effect of caffeine on phagocytosis, but it seems likely that there is an overlap in the biological and biochemical mechanisms of the cell that lead to reduction of phagocytosis and capacitation, respectively.

Insemination with semen in BTS with excess EDTA had no positive effects. Recruitment of PMNs was not inhibited and the number of non-phagocytosed spermatozoa in the uterus was just as low as in the controls.

From the present results and the results of the recent studies on inhibition of phagocytosis by caffeine (Woelders and Matthijs, 2001), and by capacitation 
(Matthijs et al., 2000), the following conclusions can be made. Shortly after insemination, the spermatozoa are still bathed in the BTS medium containing EDTA, which effectively blocks phagocytosis as well as capacitation. Most of the liquid flows back and is voided through the vulva, and about $35-45 \%$ of the spermatozoa are lost with it. The spermatozoa that were not lost with the backflow apparently have made the passage to the endometrial mucus and are thus retained. This new environment presents the conditions that allow phagocytosis, resulting in phagocytosis and digestion of large numbers of spermatozoa. In addition, these conditions allow the onset of capacitation. Spermatozoa can be fully capacitated in the uterus without ascending to the oviducts (Imai et al., 1979; Rath, 1992; Yanagimachi, 1994). Cellular changes related to capacitation then render the spermatozoa less vulnerable to phagocytes. The presence of caffeine $+\mathrm{CaCl}_{2}$ appears to advance or accelerate these processes. In addition, the presence of caffeine + $\mathrm{CaCl}_{2}$ reduces the recruitment of PMNs to the uterine lumen. In contrast, addition of high concentrations of EDTA (25 mmol $\mathrm{I}^{-1}$ ) could delay the onset of phagocytosis, but also the onset of capacitation, but is not likely to delay the recruitment of PMNs. The balance of the effects of EDTA is not positive for the number of spermatozoa in the uterus at $4 \mathrm{~h}$ after insemination.

It is concluded that backflow and phagocytosis of spermatozoa result in an extremely rapid reduction of the spermatozoa population in the uterus (to as low as $1 \%$ of the inseminated number of spermatozoa) in the first $4 \mathrm{~h}$ after insemination. The recruitment of PMNs in the $4 \mathrm{~h}$ after insemination is caused by the infusion of liquid, and is not triggered by specific factors. Optimization of the inseminate volume and sperm concentration could result in cost reduction in artificial insemination of pigs, but further studies are required. Furthermore, addition of caffeine $+\mathrm{CaCl}_{2}$ to the inseminate results in a significantly higher number of non-phagocytosed spermatozoa in the uterus of sows at $4 \mathrm{~h}$ after insemination. The number of spermatozoa recovered from the oviducts was not significantly different. However, the effect of caffeine $+\mathrm{CaCl}_{2}$ could be beneficial for the chance of fertilization, especially when ovulation takes place long after insemination. Preliminary experiments have indeed shown that addition of caffeine $+\mathrm{CaCl}_{2}$ positively affects fertilization of sows inseminated $26 \mathrm{~h}$ before ovulation (Woelders et al., 2000). More insemination studies under field conditions are currently being performed.

The authors gratefully acknowledge the financial support from the Union of Co-operative Pig Al Organizations in The Netherlands.

\section{References}

Baker RD and Degen AA (1972) Transport of live and dead boar spermatozoa within the reproductive tract of gilts Journal of Reproduction and Fertility 28 369-377
Baker RD, Dziuk PJ and Norton HW (1968) Effect of volume of semen, number of sperm and drugs on transport of sperm in artificially inseminated sows Journal of Animal Science 27 88-93

Bischof RJ, Brandon MR and Lee CS (1994) Studies on the distribution of immune cells in the uteri of prepubertal and cycling gilts Journal of Reproduction and Fertility 26 111-129

Burger JF (1952) Sex physiology of pigs Onderstepoort Journal of Veterinary Research Supplement 2 116-131

Carrasco M, Del Rio M, Hernanz A and de la Fuente M (1997) Inhibition of human neutrophil functions by sulfated and non-sulfated cholecystokinin octa peptides Peptides 18 415-422

De la Fuente M, Carrasco M and Hernanz A (1997) Modulation of human neutrophil function in vitro by gastrin Journal of Endocrinology 153 475-483

Du Mesnil du Buisson F and Dauzier L (1955) Distribution et résorption du sperme dans le tractus génital de la truie: survie des spermatozoïdes Annales D'Endocrinologie 16 413-422

Engel B and Te Brake J (1993) Analysis of embryonic development with a model for under- or overdispersion relative to binomial variation Biometrics 49 269-279

Engelhardt H, Croy BA and King GJ (1997) Role of uterine immune cells in early pregnancy in pigs Journal of Reproduction and Fertility Supplement 52 115-131

First NL, Short RE, Peters JB and Stratman FW (1968) Transport and loss of boar spermatozoa in the reproductive tract of the sow Journal of Animal Science 27 1037-1040

Fraser LR (1995) Ionic control of sperm function Reproduction, Fertility and Development 7 905-925

Friedman RL, Fiederlein RL, Glasser L and Galgiani JN (1987) Bordetella pertussis adenylate cyclase: effects of affinity-purified adenylate cyclase on human polymorphonuclear leukocyte functions Infection and Immunity 55 135-140

Genstat 5 Committee (1993) Genstat 5 Release 3 Reference Manual Clarendon Press, Oxford

Harrison RAP, Mairet B and Miller NGA (1993) Flow cytometric studies of bicarbonate-mediated $\mathrm{Ca}^{2+}$ influx in boar sperm populations Molecular Reproduction and Development 35 197-208

Harrison RAP, Ashworth PJC and Miller NGA (1996) Bicarbonate $+\mathrm{CO}_{2}$, an effector of capacitation, induces a rapid and reversible change in the lipid architecture of boar sperm plasma membranes Molecular Reproduction and Development 45 378-391

Harvath L, Robbins JD, Russell AA and Seamon KB (1991) cAMP and human neutrophil chemotaxis. Elevation of cAMP differentially affects chemotactic responsiveness Journal of Immunology 146 224-232

Hill HR, Estensen RD, Quie PG, Hogan A and Goldberg ND (1975) Modulation of human neutrophil chemotactic responses by cyclic $3^{\prime}, 5^{\prime}$ guanosine monophosphate and cyclic $3^{\prime}, 5^{\prime}$-adenosine monophosphate Metabolism 24 447-456

Imai H, Niwa K and Iritani A (1979) Time requirement for capacitation of boar spermatozoa assessed by their ability to penetrate the zona-free hamster egg Journal of Reproduction and Fertility $\mathbf{5 6}$ 489-492

Johnson LA, Aalbers JG and Grooten HJG (1988) Artificial insemination of swine: fecundity of boar semen stored in beltsville TS (BTS), modified modena (MM), or MR-A and inseminated on one, three and four days after collection Zuchthygiene 23 49-55

Kamerman E (1994) Recovery of spermatozoa from the genital tract of sows after insemination (Dutch) ID-Lelystad Report IVO-VOS Vol. 297 IDLelystad Library, PO Box 65, NL-8200 AB Lelystad, The Netherlands

Lovell JW and Getty R (1968) Fate of semen in the uterus of the sow: histologic study of endometrium during the 27 hours after natural service American Journal of Veterinary Research 29 609-625

McCullagh P (1983) Quasi-likelihood functions Annals of Statistics 11 $59-67$

Matthijs A, Harkema W, Engel B and Woelders H (2000) In vitro phagocytosis of boar spermatozoa by neutrophils from peripheral blood of sows Journal of Reproduction and Fertility 120 265-273

Pursel VG, Johnson LA and Rampacek GB (1972) Acrosome morphology of boar spermatozoa incubated before cold shock Journal of Animal Science 34 278-283 
Pursel VG, Schulman LL and Johnson LA (1978) Distribution and morphology of fresh and frozen-thawed sperm in the reproductive tract of gilts after insemination Biology of Reproduction 19 69-76

Rath D (1992) Experiments to improve in vitro fertilization techniques for in vivo-maturated porcine oocytes Theriogenology 37 885-896

Rigby JP (1966) The persistence of spermatozoa at the uterotubal junction of the sow Journal of Reproduction and Fertility 11 153-155

Rivkin I, Rosenblatt J and Becker EL (1975) The role of cyclic AMP in the chemotactic responsiveness and spontaneous motility of rabbit peritoneal neutrophils. The inhibition of neutrophil movement and the elevation of cyclic AMP levels by catecholamines, prostaglandins, theophylline and cholera toxin Journal of Immunology 115 11261134

Rodriguez-Martinez H, Nicander L, Viring S, Einarsson S and Larsson $\mathrm{K}$ (1990) Ultrastructure of the uterotubal junction in preovulatory pigs Anatomia, Histologia and Embryologia 19 16-36

Rozeboom KJ, Troedsson MH and Crabo BG (1998) Characterization of uterine leukocyte infiltration in gilts after artificial insemination Journal of Reproduction and Fertility 114 195-199

Rozeboom KJ, Troedsson MH, Molitor TW and Crabo BG (1999) The effect of spermatozoa and seminal plasma on leukocyte migration into the uterus of gilts Journal of Animal Science 77 2201-2206

Soede NM, Wetzels CCH, Zondag W, De Koning MAI and Kemp B (1995) Effects of time of insemination relative to ovulation, as determined by ultrasonography, on fertilization rate and accessory sperm count in sows Journal of Reproduction and Fertility 104 99-106

Steverink DWB, Soede NM, Bouwman EG and Kemp B (1998) Semen backflow after insemination and its effect on fertilisation results in sows Animal Reproduction Science 54 109-119

Viring S (1980) Distribution of live and dead spermatozoa in the genital tract of gilts at different times after insemination Acta Veterianaria Scandinavica 21 587-597

Viring S and Einarsson S (1980) Influence of boar seminal plasma on the distribution of spermatozoa in the genital tract of gilts Acta Veterinaria Scandinavica 21 598-606

Viring S and Einarsson S (1981) Sperm distribution within the genital tract of naturally inseminated gilts Nordisk Veterinaermedicin 33 145-149

Woelders and Matthijs (2001) Phagocytosis of boar spermatozoa in vitro and in vivo. Reproduction Supplement 58 113-127

Woelders H, Matthijs JJ, Bouwman EG and Soede NM (2000) Caffeine plus $\mathrm{Ca}^{2+}$ reduces uterine leukocyte recruitment and sperm phagocytosis and improves fertility in pig AI. In 14th International Congress on Animal Reproduction Stockholm 2-6 July 2000 Abstracts Vol. 2 p 94 Abstract 15:20 ICAR-2000, Stockholm

Yanagimachi R (1994) Mammalian fertilization. In The Physiology of Reproduction 2nd Edn pp 189-317 Eds E Knobil and JD Neill. Raven Press, New York

Received 21 August 2002.

First decision 28 October 2002.

Revised manuscript received 28 November 2002.

Accepted 3 December 2002. 